\title{
INTERNET DAS COISAS (IOT): AS CONSEQUÊNCIAS DA COMPUTAÇÃO UBÍQUA NA SOCIEDADE
}

\author{
Thiago Seti Patricio ${ }^{1}$, Matheus Teixeira ${ }^{2}$, Maria da Graça Mello Magnoni ${ }^{3}$, Francisco Rolfsen Belda ${ }^{4}$ \\ ${ }^{1}$ Mestrando em Mídia e Tecnologia pela Faculdade de Arquitetura, Artes e Comunicação da Universidade Estadual \\ Paulista - UNESP, Bauru, SP. E-mail: thiago-2-pc@hotmail.com \\ ${ }^{2}$ Mestrando em Mídia e Tecnologia pela Faculdade de Arquitetura, Artes e Comunicação da Universidade Estadual \\ Paulista - UNESP, Bauru, SP. E-mail: matheusteixeira.com@outlook.com \\ ${ }^{3}$ Doutora em Educação pela Universidade Estadual Paulista - UNESP, Marília, SP. Professora e pesquisadora do \\ Departamento de Educação da Faculdade de Ciências da Universidade Estadual Paulista - UNESP, Bauru, SP. E-mail: \\ sofia@fc.unesp.br \\ ${ }^{4}$ Doutor em Engenharia de Produção pela Universidade de São Paulo - USP. Professor do Departamento de \\ Comunicação Social da Faculdade de Arquitetura, Artes e Comunicação da Universidade Estadual Paulista - UNESP, \\ Bauru, SP. E-mail: belda@faac.unesp.br
}

\section{RESUMO}

O presente artigo apresenta uma análise de conceitos e utilidades que perpassam a computação ubíqua e a Internet das Coisas (IOT) com o objetivo de demonstrar as consequências da ubiquidade no cotidiano das pessoas. Nesta pesquisa é possível verificar que os autores fazem relatos detalhados de produtos ou serviços de IoT. Para isso, consultaram artigos e reportagens sobre criações que estavam em prática de 2014 a 2017. O ponto central deste artigo é mostrar exemplos reais de aplicações de loT e os efeitos da computação ubíqua na sociedade, como: surgimento de um novo tipo de usuário, denominado ubíquo; interatividade entre médicos e pacientes; dispositivos vestíveis; entre outros. Destaca-se que uma nova base de relações e aquisição de informações é estabelecida com a conectividade de objetos à Internet, tais como geladeiras, televisores, carros, pulseiras, óculos e relógios.

Palavras-chave: Internet das Coisas. Computação ubíqua. Informação. Tecnologia. Mídias digitais.

\section{INTERNET OF THINGS (IOT): THE CONSEQUENCES OF UBIQUITOUS COMPUTING IN SOCIETY}

\begin{abstract}
This paper presents an analysis of concepts and uses that go through ubiquitous computing and Internet of Things (IOT) in order to demonstrate the ubiquity consequences in people's daily lives. In this research, it is possible to verify that the authors make detailed reports of IoT products or services. For that, they consulted articles and reports on creations that were in practice from 2014 to 2017. The main point of this paper is showing loT's real examples and the effects of ubiquitous computing on society, such as: the appearance of a new kind of user, called ubiquitous; interactivity between doctors and patients; wearable devices; among others. It stands out that a new base of relationships and information acquisition is established with a connectivity of objects to the Internet like refrigerators, televisions, cars, bracelets, glasses, and watches.
\end{abstract}

Keywords: Internet of Things. Ubiquitous computing. Information. Technology. Digital media.

INTRODUÇÃo
Com as Tecnologias da Informação e
$\begin{array}{cccc}\text { Comunicação } & (\text { TICs })^{1} \text { emergentes, na }\end{array}$

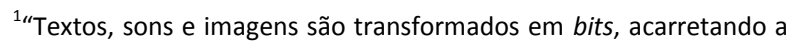
substituição das diferentes tecnologias que eram necessárias para contemporaneidade surge o conceito de Internet

as várias transmissões analógicas (telégrafo para texto, telefonia para voz, radiodifusão para sons e imagens, etc.), por redes integradas de usos múltiplos (via cabo ótico, satélites ou radiodigitais)." (OLIVEIRA, 2003, p. 85, grifo do autor). 
das Coisas (Internet of Things - loT, em inglês), por vezes também chamada, em inglês, de Machine-to-Machine (M2M - máquina a máquina, em tradução livre). Apresenta-se como uma revolução da Internet tradicional, tão abrangente quanto à criação desta e que "[...] refere-se às tecnologias que permitem ambas tecnologias com ou sem fio a se comunicarem com outros dispositivos que possuam a mesma habilidade." (PINOCHET, 2014, p. 201).

Partindo desse princípio, nem sempre os usuários se dão contam de que estão conectados, conceito este denominado computação ubíqua. Moreira Filho (2014) explana que a gênese deste termo deu-se por meio do pesquisador Mark Weiser, da Xerox Palo Alto Research Center (Parc), que acreditava que a utilização de computadores pessoais não seria o ponto alto da computação, mas apenas mais um passo na busca para se atingir o verdadeiro e real potencial das TICs, no caso, a ubiquidade.

Weiser (1991) explica, no artigo The Computer for the 21st Century ("O computador para o século 21 ", em tradução livre), que a principal característica das tecnologias de computação ubíqua é a capacidade que elas têm de se misturarem e se adaptarem às atividades do indivíduo. Salienta, ainda, que a imersão cotidiana em tecnologias ubíquas está intimamente relacionada com fatores psicológicos, haja vista que as pessoas não devem pensar que as estão utilizando, ou seja, simplesmente acabam por deixar de perceber que estão conectadas.

A loT -, que trata da conexão à Internet por objetos do dia a dia, como TVs, automóveis, notebooks, smartphones, webcams, consoles de jogos, entre outros, - proverá ubiquidade, destaca Almeida (2015), pois a informação irá fluir por todos os lugares, a todo tempo e em qualquer situação. Será de forma adaptada e integrada ao cotidiano das pessoas, principalmente por meio de dispositivos inteligentes e vestíveis, como pulseiras, relógios e óculos. Como a loT tem como premissa a colaboração direta entre sensores inteligentes, a fim de criar uma gama de aplicações inteligentes, as tomadas de decisão poderão ocorrer sem a intervenção humana (AL-FUQAHA et al., 2015).

Ao constatar-se a imensa soma de suportes digitais proporcionada pela computação ubíqua, nota-se que, em concomitância com o crescimento da Internet, cresce cada vez mais a quantidade de dados presentes no ciberespaço ${ }^{2}$. Por sua vez, consolida-se uma rede digital universal de relações sociais, intelectuais, artísticas e éticas, além de ideias e práticas (MARTINO, 2015, p. 27), conhecida como cibercultura ${ }^{3}$.

Logo, pode-se afirmar que a computação ubíqua traz consigo, conforme discurso de Santaella (2013), mudança nos processos de aprendizagem, pois a informação não está presente apenas em livros e materiais impressos, mas também em periféricos e dispositivos que podem transmitir a informação para qualquer lugar, tornando completamente onipresente o acesso, a transmissão, a recepção e o compartilhamento de informações e, por conseguinte, de conhecimento.

Em face de que foi apresentado acima, o presente trabalho objetiva, portanto, compreender algumas aplicações e consequências da computação ubíqua no desenvolvimento da sociedade contemporânea, com foco na loT, que permite mais interação entre usuários e equipamentos, bem como entre dispositivos.

\section{PRESSUPOSTOS TEÓRICOS}

Atualmente, com o avanço no desenvolvimento de novas TICs, os sistemas tornam-se cada vez mais ubíquos na vida das pessoas e proporcionam transparência de uso a partir de uma maior colaboração e conectividade, podendo-se observar tecnologias como os dispositivos vestíveis e de loT, que dão sentido ao tempo da computação ubíqua. Na definição de Martino (2015, p.11), a ubiquidade ocorre justamente desse modo, quando as mídias digitais conectadas em rede ficam presentes em todos os lugares e conseguem realizar conexões em qualquer tempo e espaço.

\footnotetext{
2 "Eu defino o ciberespaço como o espaço de comunicação aberto pela interconexão mundial dos computadores e das memórias dos computadores." (LÉVY, 1999, p. 94, grifo do autor). Ainda segundo o autor, é um dispositivo interativo e comunitário (1999, p. 29) que induz a inteligência coletiva (1996, p. 128) e é representado, entre outros, por (1998, p. 104): hipertexto, multimídia interativa, simulação, realidade virtual, telepresença, realidade aumentada e vida artificial.

${ }^{3}$ Para Pierre Lévy, a cibercultura é um universal sem totalidade. “O que é o universal? É a presença (virtual) da humanidade em si mesma. Quanto à totalidade, podemos defini-la como a conjunção estabilizada do sentido de uma pluralidade (discurso, situação, conjunto de acontecimentos, sistema etc.). [...] A cibercultura, por outro lado, mostra precisamente que existe uma outra forma de instaurar a presença virtual da humanidade em si mesma (o universal) que não seja por meio da identidade do sentido (a totalidade)." (LÉVY, 1999, p. 123)
} 
De acordo com Junges, Klein e Barbosa (2014), a computação ubíqua diz respeito a uma revolução da computação, que advém do rápido avanço de tecnologias móveis, bem como do uso da loT por meio de sensores embutidos em coisas do dia a dia. Ainda segundo os autores, a computação ubíqua pode ser considerada um assunto emergente no campo das pesquisas científicas por possuir características interdisciplinares, estando intrinsecamente ligada às áreas de Engenharias, Telecomunicações e Ciência da Computação.

As tecnologias mais relevantes são aquelas que, na visão de Weiser (1991), desaparecem na vida das pessoas, ou seja, fluem com as atividades rotineiras de forma que 0 indivíduo esteja conectado sem perceber. 0 autor salienta que o computador pessoal é, por assim dizer, apenas mais uma etapa de transição a fim de se atingir o verdadeiro potencial das TICs, que é o de tornar a computação parte integrante da vida das pessoas em todas as esferas de atuação, em todos os lugares e a todo instante.

Para Capobianco (2010), o principal meio norteador da comunicação e difusão da informação na atual Era do Conhecimento ${ }^{4}$ é a Internet, que teve seus primórdios entre as décadas de 1950 e 1960 com fins militares norteamericanos (MARTINO, 2015, p. 12). Precisamente no ano de 1969, o:

Governo dos Estados Unidos cria a Arpanet, uma rede experimental com quatro computadores. Eles operam em Stanford, Universidade da Califórnia, Los Angeles (Ucla), UC Santa Barbara e Universidade de Utah. [...] A Arpanet mais tarde se transforma na Internet, a rede mundial de computadores.

(MOHERDAUI, 2002, p.32)

\footnotetext{
${ }^{4}$ "Era do conhecimento - Essa etapa corresponde ao início dos anos 90, surgindo nesse período o termo TIC, em substituição ao termo Informática. Nessa fase, a informação passa a ser encarada como um ativo das organizações, e a sua disseminação e disponibilização tornam-se um diferencial fundamental nos mercados competitivos. Deste modo, as TIC tornam-se estratégicas para as empresas, surgindo inúmeras aplicações em setores-chave, como o planejamento, marketing, recursos humanos e automação de escritórios." (OLIVEIRA, 2003, p. 113).
}

Na década de 1970, outras instituições integraram a rede inicial, como também foram criados protocolos de transmissão que permitiam a troca de dados e informações entre computadores (CAPOBIANCO, 2010). Para mais, em 1989 foi concebido por Tim Berners-Lee o projeto World Wide Web (W3C, 2017), o principal elemento propulsor para a rápida expansão e abrangência da Internet, e cujo objetivo foi o de propiciar o compartilhamento e acesso a informações em forma de vídeos, áudios, documentos, gráficos, textos, entre outros, por meio de endereços denominados websites, que permitem essa interligação (CAPOBIANCO, 2010).

Estudos apontam que a difusão da Internet advém dessa capacidade de armazenar, processar e comunicar informações, fato este que vem crescendo massivamente nos últimos anos, decorrente do avanço das TICs. A evolução sistemática da sociedade é um reflexo desse avanço, visto que a informação permeia todos os espaços e atua em todas as atividades humanas e camadas sociais. Assim, nesse contexto é que surge a loT, uma nova forma de transmissão de informações entre homem e máquina (e entre máquina e máquina), que traz elementos potencializadores da Web 3.0, "[...] um caminho evolutivo até a inteligência artificial, a realização da web semântica e da arquitetura orientada a serviço e a evolução em direção ao 3D." (PINOCHET, 2014, p. 172).

Com base nesse viés, a loT pode ser definida como uma ampliação da Internet. E seu principal objetivo é o de proporcionar que objetos do cotidiano, como celulares, geladeiras, micro-ondas, televisores, carros, roupas, consoles de jogos, portas, entre outros, possam se conectar a Internet através de sensores inteligentes que concedem a esses objetos a capacidade de comunicação e processamento de dados e informações.

Dias (2013, p.1) define o termo loT como:

[...] infraestrutura de rede global, interligando objetos físicos e virtuais por meio da exploração de captura de dados e capacidades de comunicação. Essa infraestrutura inclui a internet existente e em evolução, bem como os desenvolvimentos de rede. 
Ela oferecerá identificação de objetos específica, capacidade de sensoriamento e de conexão como base para o desenvolvimento de aplicações e serviços independentes

cooperativos. Estes serão caracterizados por um elevado grau de captura autônoma de dados, transferência de eventos, conectividade

interoperabilidade de rede.

Ademais, a expressão loT surgiu em 1999 no Massachusetts Institute of Technology (MIT) a partir de pesquisas de um grupo que trabalhava inicialmente na área de identificação por radiofrequência (Radio-Frequency Identification - RFID), bem como em tecnologias de sensores. Outrossim, as pesquisas eram conduzidas por laboratórios divididos em sete universidades espalhadas por quatro continentes. Nesse contexto, a Internet tradicional evoluiu para algo sensorial, na qual elementos como iluminação, vibração, pressão, temperatura, umidade, etc., passaram a trafegar pela rede mundial de computadores por meio de dispositivos inteligentes e aplicações revolucionárias (EVANS, 2011).

Aquino (2015) destaca que os dispositivos que são e serão conectados na loT possuem como alicerce o conceito de Rede de Sensores sem Fio (RSSF), que é um conjunto de periféricos e dispositivos que se transformam em um grande sistema distribuído cooperativamente. É igualmente correto afirmar que a linha entre o mundo físico e o digital tem se tornado mais tênue. Arruda (2016) descreve, por exemplo, que a loT já é chamada até de Internet de Todas as Coisas (Internet of Everything, em inglês). Porém, ambos os termos são utilizados para o propósito de conectar o máximo de coisas à Internet com o intuito de proporcionar experiências únicas e, até então, inesperadas.

A loT provê, na explicação de Evans (2011), uma enorme gama de aplicativos para o monitoramento e controle com potencial de melhorar consideravelmente a forma como as pessoas se comunicam, trabalham e vivem, pois trata da interligação de redes heterogêneas. Um exemplo é a inserção de sensores minúsculos, conectados à Internet, em animais, plantas e carros - com isso, cria-se uma nova rede de conhecimento, que envolve a aquisição de dados e informações por meio de objetos e aplicativos de automatização. Destarte, com o avanço tecnológico, novos objetos são agregados à loT.

Estudos realizados pela International Data Corporation (IDC) em 2014 apontam que a informação digital dobra a cada dois anos, tamanho é o volume de dados produzidos pela humanidade. A pesquisa ainda mostra que a principal tendência responsável por esse crescimento gigantesco é justamente a loT, que deverá corresponder sozinha a $10 \%$ de toda a informação útil gerada digitalmente no planeta até 2020 (GREGO, 2014).

Cabe ressaltar que a implantação da IoT também esbarra em pontos importantes, como a segurança das informações e a padronização de comunicação, já que os sensores que integram os objetos na IoT possuem protocolos diferentes dos utilizados na tradicional configuração homem-máquina. Contudo, os provedores de serviços já trabalham para transpor essas barreiras (EVANS, 2011).

Sabe-se, também, que o volume de dados e informações digitais provenientes das TICs cresce a níveis colossais. No entanto, muitos são difíceis de serem mensurados, pois em sua maioria são dados semiestruturados e não estruturados, ou seja, incompletos, irregulares e aparentemente sem valor algum, ou não são integrados para as tomadas de decisão. Santos et al. (2016) salientam que os dados obtidos na loT podem demonstrar imperfeições e ruídos, inconsistência, e serem de tipos distintos. Portanto, o conglomerado de tecnologias que constituem a IoT devem seguir os mesmos padrões que uma rede tradicional para que as informações trafeguem sem interferências.

Conforme reportagem de Machado (2014) para o site do O Globo, a sociedade está imergindo na loT devido à expansão do universo digital. Estima-se que uma família comum consiga registrar informações no montante de aproximadamente 65 iPhones de 32GB por ano, podendo chegar a 318 desses smartphones em 2020. Tais informações continuarão crescendo em proporções espantosas, de acordo com pesquisa realizada pela EMC Corporation, que aponta também que o volume de dados e informações já ultrapassa o limite de 
armazenamento disponível no mundo, o que só não acarreta em overflow (transbordar, em tradução livre) devido a grande maioria das informações serem criadas em caráter temporário, por exemplo, em jogos ou plataformas como a Netflix ${ }^{5}$.

A loT tende a se tornar onipresente na rotina das pessoas, e a heterogeneidade de dispositivos conectados à Internet é o elemento crucial para o sucesso desse amplo conceito. Deste modo, a pluralidade de informações que surge do acesso à loT, e da interação desses objetos digitais e inteligentes com a Internet, potencializa o surgimento de aplicações que visem melhorar a qualidade de vida do homem, bem como o sensoriamento de ambientes de difícil acesso.

\section{MATERIAL E MÉTODOS}

Esta é uma pesquisa com o tipo de abordagem qualitativa, afinal, considera todos os elementos encontrados durante a confecção do texto. Na definição de Barros e Duarte (2009, p. 62-63), a pesquisa qualitativa reflete que:

$$
\begin{aligned}
& \text { [...] os dados não são } \\
& \text { apenas colhidos, mas } \\
& \text { também resultado de } \\
& \text { interpretaçãor e } \\
& \text { reconstrução pelo } \\
& \text { pesquisador, em diálogo } \\
& \text { inteligente e crítico com } \\
& \text { a realidader Nesse } \\
& \text { percurso de descobertas, } \\
& \text { as perguntas permitem } \\
& \text { explorar um assunto ou } \\
& \text { aprofundá-lo, descrever } \\
& \text { processos e fluxos, } \\
& \text { compreender o passado, } \\
& \text { analisar, discutir e fazer } \\
& \text { prospectivas. }
\end{aligned}
$$

Do ponto de vista da natureza do corpus, a metodologia utilizada para este trabalho é a chamada pesquisa básica, cujo objetivo principal é o de proporcionar novos conhecimentos para o desenvolvimento da ciência sem que haja envolvimento de uma aplicação prática (GERHARDT; SILVEIRA, 2009, p. 34).

\footnotetext{
${ }^{5}$ Serviço de streaming, que é uma "[...] forma de transmitir áudio e/ou vídeo através de uma rede de computadores sem a necessidade de downloads de arquivos, pois a máquina recebe as informações ao mesmo tempo em que as disponibiliza para seus usuários." (AVILA, 2008, p.137).
}

Como pesquisa descritiva que é, o presente documento, como $o$ nome sugere, carrega a função de descrever o fenômeno da computação ubíqua e da loT e como interferem na sociedade. Quanto a este tipo de objetivo de pesquisa, "[...] uma de suas características mais significativas está na utilização de técnicas padronizadas de coleta de dados, tais como o questionário e a observação sistemática." (GIL, 2002, p. 42).

Neste estudo opta-se pela observação direta intensiva de produtos ou serviços de loT no período de 2014 a 2017. Os exemplos são selecionados pelos autores com base na relevância que têm, seja nacional ou internacional. Tal observação é uma forma de documentação direta, que "não consiste apenas em ver e ouvir, mas também em examinar fatos ou fenômenos que se deseja estudar." (MARCONI; LAKATOS, 2010, p. 205).

Além da observação direta intensiva, sistemática e não participante, lança-se mão, como outra técnica de pesquisa, da documentação indireta por meio da pesquisa bibliográfica, uma etapa imprescindível ao trabalho. Portanto, é feita uma análise crítica da literatura sobre TICs, especialmente de livros, artigos científicos e reportagens jornalísticas que enfocam em ubiquidade e a loT.

$$
\begin{aligned}
& \text { Pesquisa bibliográfica, } \\
& \text { num sentido mais amplo, } \\
& \text { é o planejamento global } \\
& \text { inicial de qualquer } \\
& \text { trabalho de pesquisa que } \\
& \text { vai desde a identificação, } \\
& \text { localização e obtenção da } \\
& \text { bibliografia permite } \\
& \text { sobre o assunto, até a } \\
& \text { apresentação de um } \\
& \text { texto sistematizado, } \\
& \text { onde é apresentada toda } \\
& \text { a literatura que o aluno } \\
& \text { examinou, de forma a } \\
& \text { evidenciar } \quad 0 \\
& \text { entendimento do } \\
& \text { pensamento dos autores, } \\
& \text { acrescido de suas } \\
& \text { próprias idéias e } \\
& \text { opiniões. (BARROS; } \\
& \text { DUARTE, 2009, p. 51) }
\end{aligned}
$$

Ademais, é a leitura que, segundo Freires (2007), fornece subsídios para a criação de novos textos oriundos do ato de instigar ideias, algo que auxilia o indivíduo a conectar conjuntos de pesquisa e conceitos, o que por sua 
vez garante a base de sustentação do trabalho e permite alcançar os objetivos propostos.

Segundo Marconi e Lakatos (2010), o trabalho de pesquisa visa à correlação entre os dados e informações levantados com o universo teórico. Assim, serve de embasamento para nortear e fundamentar o desenvolvimento de um trabalho científico de caráter interpretativo. As autoras explanam, ainda, que o referencial teórico é fundamental, uma vez que as fontes bibliográficas ou documentais utilizadas contêm aspectos iguais ou semelhantes aos da pesquisa pretendida. Assim, no tópico a seguir é possível verificar a prática do esforço metodológico descrito acima.

\section{RESULTADOS E DISCUSSÕES}

As TICs que compõem o ciberespaço estão criando uma forma de aprendizado cognitivo, no qual o estudante ou qualquer integrante da sociedade emprega mente, intelecto e cérebro na compreensão de informações advindas da Internet. Por sua vez, também surge um novo tipo de usuário, denominado ubíquo, que se caracteriza pela habilidade de imergir na Internet e estabelecer, sozinho, uma nova ordem informacional, buscando informações em diversas aplicações e aplicativos disponíveis no mundo virtual, desprendendo-se, assim, das fronteiras do espaço físico, visto que a Internet é o principal elemento propulsor responsável por tal fato (SANTAELLA, 2013).

Pode-se afirmar que, atualmente, o acesso à informação tornou-se algo absolutamente ubíquo, sob a égide dos processos de aprendizagem abertos - que, conforme Santaella (2013), são espontâneos. O sujeito se vale do acesso livre e contínuo à informação para, posteriormente, comunicar e adquirir conhecimento. E para o presidente executivo da Alphabet Inc. (empresa que controla o Google), Eric Schmidt, o acesso à Internet feito majoritariamente por um computador pessoal irá acabar e a conexão em outros dispositivos nem será conscientemente percebida. "Ele acredita que no futuro a internet estará tão integrada ao dia a dia da população que não fará sentido pensar em uma vida desconectada, ou seja, teremos um novo conceito de internet e de como ela será empregada na rotina." (A INTERNET... 2015)

A conexão de objetos à Internet, como geladeiras, relógios, pulseiras, carros, televisores, entre outros, já é uma realidade, e segundo reportagem de Oliveira (2016) para o portal UOL, a loT tem grande potencial de mercado, principalmente no setor da indústria. Por exemplo: os bueiros conectados, um projeto piloto da empresa Net Sensors, cujo objetivo é controlar, por meio de sensores inteligentes, o nível de sujeira contida em bueiros e lixeiras, e em seguida, a partir dessa informação, efetuar o processo de limpeza de maneira mais eficiente. $O$ projeto foi testado nas cidades de São Paulo (SP) e Rio de Janeiro (RJ) no ano de 2016 e constatouse, com sua aplicação, que cerca de $50 \%$ dos bueiros limpos todos os dias não possuíam mais sujeira a ser removida.

Em Águas de São Pedro (SP) existe um projeto de digitalização da cidade. Entre as tecnologias, está o estacionamento inteligente, onde as vagas demarcadas com tinta no asfalto possuem sensores equipados em uma lâmpada que sinaliza de forma contínua. Funciona do seguinte modo: acendem uma luz vermelha quando a vaga está ocupada e uma luz verde caso esteja livre. Ademais, são conectados ao aplicativo "Onde Parar", que indica com exatidão os locais com estacionamento livre. Ressalta-se que os sensores são abastecidos com energia renovável e alternativa que vem do sol (VICENTIN, 2015).

Outra tecnologia de loT implementada em Águas de São Pedro é o aplicativo para smartphones "Águas sem dengue", que visa auxiliar agentes da vigilância epidemiológica no combate aos focos do mosquito Aedes aegypti, o que, de acordo com Vicentin (2015), já gerou resultados interessantes, pois, a população pôde tirar fotos de possíveis focos e enviá-las diretamente à base do sistema de saúde. De acordo com a secretaria municipal de saúde, isso resultou na queda de 86 para 28 casos de dengue na cidade em 2015.

No setor de educação, Águas de São Pedro também investiu em tecnologias de loT ao adotar o projeto de digitalização das escolas municipais, distribuindo cerca de 600 tablets a crianças e, também, realizando treinamento de professores a fim de que essas tecnologias auxiliassem no ensino-aprendizagem. $O$ resultado foi de evasão zero das aulas, bem como de aumento na capacidade de atenção (VICENTIN, 2015).

Segundo McEwen e Cassimally (2014), os objetos que dão forma à loT são aplicativos do cotidiano, de utilidade de qualquer ser humano, 
seja em casa, no trabalho, na escola, no carro ou até mesmo ao redor de seu corpo durante a prática de atividades físicas. Têm como principal característica um sensor inteligente que os capacita a receber dados do mundo real e enviálos à Internet para processamento e tratamento, com a finalidade de gerar informações úteis para determinadas tomadas de decisão. Como exemplo, um pedômetro instalado no tênis de um corredor, em conjunto com um monitor cardíaco, pode fornecer informações valiosas sobre velocidade, batimentos cardíacos, distância percorrida e calorias queimadas. Todos esses dados podem ser enviados de maneira automática para uma base de dados em nuvem de websites de rastreamento de atividades físicas.

Também podem ser integrados em conversas polissêmicas, como em redes sociais virtuais, prontuários eletrônicos de pacientes ou e-commerce - neste, é capaz de informar ao praticante de atividades físicas o quanto de caloria ele ingeriu entre uma compra e outra (McEWEN; CASSIMALLY, 2014). Com base no exemplo supracitado, pode-se afirmar que as tecnologias vestíveis (wearables, em inglês), como camisetas, óculos, pulseiras, relógios e tênis com sensores sem fio e nanotecnologia, contribuem para a expansão da loT.

A IoT também colaborou, como comprova reportagem da revista Galileu (INTERNET... 2015), para evitar desastres em infraestruturas, como vazamentos em oleodutos, emergências em rodovias e defeitos na estrutura de pontes e linhas de transmissão. Assim, uma das opções da loT na detecção de desastres é o software REFS, da empresa Via Science, com sede em Cambridge, no Estado de Massachusetts (EUA). Ele possui a capacidade de analisar dados em tempo real por meio de sensores inteligentes que detectam anomalias previamente estabelecidas a fim de emitir alertas, sendo que tais sensores são instalados em drones, que por sua vez são os responsáveis por realizar a inspeção - até então era feito por helicópteros e aviões com especialistas, o que gerava custo alto devido ao risco de acidentes e da distância da região a ser inspecionada (INTERNET... 2015).

Outrossim, outro exemplo da evolução da loT são as casas inteligentes, onde móveis e eletrodomésticos possuem sensores que as capacitam a reconhecer peso, pulsação, temperatura e até mesmo conversar com os moradores, de modo a auxiliar nas tarefas domésticas. Geus, Grégio e Melo (2015) dão mais exemplos: luzes de uma casa podem se acender a partir de um comando de celular; detecção de vazamentos nos sistemas que distribuem água; monitoramento de situações ambientais que podem impactar na saúde das pessoas; entre outras aplicações. Como adendo, os autores ressaltam que atualmente já há geladeiras que avisam a falta de algum alimento, e no futuro bem próximo poderão automaticamente fazer, aos supermercados, pedidos de reposição.

Sob tal enfoque, o Japão pretende lançar no mercado, no ano de 2020 , um conjunto de produtos com fins de automatização do lar, análogo à linha de produtos do seriado futurista Os Jetsons, produzido na década de 1960 pela Hanna-Barbera. As aplicações devem ter sensores para identificar pulsação e peso, máquinas de lavar que eliminam o desperdício de água ao constatar a quantidade de sujeiras nas roupas, câmeras de reconhecimento facial para a abertura de portas, sensores que controlam a luminosidade e temperatura nos cômodos, bem como diversas outras funções (CUNHA, 2014).

A ideia das casas inteligentes é fazer com que os cômodos sejam monitorados remotamente de maneira harmoniosa e que haja economia geral com energia elétrica e específica de luminosidade e eletrodomésticos (SILVA et al., 2015). Ainda há as cidades inteligentes, que são modificadas por meio das tecnologias digitais de forma a propiciarem mais qualidade de vida, sustentabilidade e governança aos cidadãos, como pôde ser visto no caso de Águas de São Pedro (SP), considerada a primeira cidade digital brasileira.

Ainda no tocante à qualidade de vida das pessoas, a loT se mostra importante quando proporciona mais eficiência dos serviços. Como exemplo, há um projeto em andamento no primeiro semestre de 2017, da Prefeitura do Rio de Janeiro e do Ministério da Ciência, Tecnologia, Inovações e Comunicações, realizado na comunidade da Rocinha, onde os moradores recebem um sensor para medição de índice glicêmico. A saber, essas informações são enviadas para o hospital da região e avaliadas pelo corpo médico, que busca possíveis irregularidades. Caso as encontre, um sinal é emitido de volta ao sensor em forma de alarme, indicando que o paciente deve locomover-se à unidade hospitalar (BRASIL, 2017).

$$
\text { É também com a }
$$$$
\text { tecnologia de loT que o }
$$ 
Centro Nacional de Monitoramento e Alertas de Desastres Naturais (Cemaden) consegue monitorar, com precisão, a movimentação de terra em morros e encostas com risco de deslizamento.

Plataformas de coletas de dados, compostas por pluviômetro e sensores de umidade, reúnem informações sobre a quantidade de chuva acumulada e de água no solo. Os equipamentos transferem os dados pela internet diretamente para a Sala de Controle do Cemaden, em Cachoeira Paulista (SP), onde são tomadas as decisões para diminuir os impactos dos desastres naturais. A iniciativa está em fase de testes em nove municípios do país (BRASIL, 2017).

O que mais chama a atenção é o fato de que os equipamentos de tecnologia disponíveis no mercado automatizam serviços do cotidiano. A loT, como parte intrínseca da computação ubíqua, pode criar inúmeras aplicações que permitam ao ser humano transferir consumos de espaço temporal para um determinado objeto. Há muitas possibilidades, tais como um automóvel que possa identificar a frequência cardíaca do motorista, podendo, assim, monitorar e identificar um possível infarto e, então, acionar socorro (POPOVICI, 2012).

\section{CONCLUSÃO}

Este trabalho apresenta uma visão geral da computação ubíqua, alicerçada especialmente pelo fenômeno da IoT. Segundo relevantes pesquisas consultadas pelos autores, a Internet das Coisas será uma revolução do mundo on-line por meio da conectividade universal - em qualquer lugar, de maneira imediata e veloz - de pessoas a objetos que outrora não estavam na Internet.

A computação ubíqua tem como base a mudança na interatividade entre usuários, transformando-se em algo natural, imperceptível, proativo e principalmente onipresente, a fim de integrar informações e auxiliar em áreas como da Medicina, Educação, Infraestrutura, nos negócios e na sociedade como um todo. Assim como a Internet tradicional, que ganhou status de revolução tecnológica ao conectar computadores ao redor do mundo, a loT surge como um serviço que auxilia as pessoas em tarefas rotineiras, bem como a alterar a forma como os seres humanos interpretam o mundo.

Consequentemente, pode-se reiterar que a loT é um meio de otimizar a busca por informações. O potencial de utilização da computação ubíqua é limitado, então, tão somente pela imaginação de quem interage por meio dela e com ela. Frisa-se que, nos dias atuais, as tecnologias tendem a ficarem mais próximas do ser humano, principalmente as digitais, que estão tornando-se inteligentes e favorecendo uma oferta sem igual de informações, que podem vir a potencializar o processo de aprendizagem informal. Porém, é necessário, conforme elucida Santaella (2013), que esta esteja em consonância com a educação formal, que é o método tradicional de escolas e instituições de ensino superior.

Por fim, com a conclusão deste estudo, sugere-se, para trabalhos complementares futuros, que pesquisadores disponham-se a analisar os conceitos de computação ubíqua e IoT apresentados e abordem o apoio deles para um processo de ensino-aprendizagem mais sólido, uma vez que hoje há transdisciplinaridade entre a educação formal, com supervisão de tutores e docentes, e a aprendizagem informal, que ocorre, numa das formas, com a imersão no ciberespaço para troca de informações e saberes, além de enriquecimento da cibercultura e aumento da exploração das capacidades humanas.

\section{REFERÊNCIAS}

A INTERNET... 'A internet desaparecerá', diz diretor-executivo do Google em Davos. Folha de S.Paulo, São Paulo, 24 jan. 2015. Disponível em: <http://www1.folha.uol.com.br/mercado/2015/0 1/1580022-a-internet-desaparecera-diz-diretorexecutivo-do-google-em-davos.shtml>. Acesso em: 07 mai. 2017.

AL-FUQAHA, A.; GUIZANI, M.; MOHAMMED, M.; ALEDHARI, M.; AYYASH, M. Internet of things: a survey on enabling technologies, protocols and applications. 2015. Disponível em: 
$<$ http://citeseerx.ist.psu.edu/viewdoc/download? doi=10.1.1.720.4460\&rep=rep1\&type=pdf $>$.

Acesso em: 07 mai. 2017.

ALMEIDA, H. Apresentação: internet das Coisas: tudo conectado. Computação Brasil, Porto Alegre, n. 29, abr. 2015. Disponível em: <http://www.sbc.org.br/images/flippingbook/co mputacaobrasil/computa_29_pdf/comp_brasil_2 015_4.pdf >. Acesso em: 07 mai. 2017.

AQUINO, A. Sensores conectados em rede. Computação Brasil, Porto Alegre, n. 29, abr. $2015 . \quad$ Disponível em: <http://www.sbc.org.br/images/flippingbook/co mputacaobrasil/computa_29_pdf/comp_brasil_2 015_4.pdf >. Acesso em: 07 mai. 2017.

ARRUDA, P. ... e a Internet de todas as coisas? Computerworld, São Paulo, 13 jan. 2016. Disponível em: <http://computerworld.com.br/einternet-de-todas-coisas $>$. Acesso em: 07 mai. 2017.

BRASIL. Ministério da Ciência, Tecnologia, Inovações e Comunicações. Assessoria de Comunicação Social. Internet das Coisas melhora a qualidade de vida ao garantir maior eficiência nos serviços. Brasília, 01 mar. 2017. Disponível em: <http://www.mcti.gov.br/pagina-noticia//asset_publisher/lqV53KMvD5rY/content/interne t-das-coisas-melhora-a-qualidade-de-vida-aogarantir-maior-eficiencia-nosservicos;jsessionid=EB3788505FF7B29FE6BBB774 94BDF3F3.rima>. Acesso em: 07 mai. 2017.

AVILA, R. N. P. Streaming: aprenda a criar e instalar sua rádio ou TV na Internet. Rio de Janeiro: Ciência Moderna, 2008.

BARROS, A.; DUARTE, J. (Orgs.). Métodos e técnicas de pesquisa em comunicação. 2.ed. São Paulo: Atlas, 2009.

CAPOBIANCO, L. A Revolução em curso: Internet, sociedade da informação e cibercultura. Estudos em Comunicação, Covilhã, v. 2, n. 7, p. 175-193, mai. 2010. Disponivel em: <http://www.ec.ubi.pt/ec/07/vol2/capobianco.p df>. Acesso em: 07 mai. 2017.

CUNHA, J. Desenvolvida no Japão, casa inteligente chega ao mercado em 2020. Folha de S.Paulo, Tóquio, 30 nov. 2014. Disponível em:
$<$ http://www1.folha.uol.com.br/mercado/2014/1 1/1555332-desenvolvida-no-japao-casainteligente-chega-ao-mercado-em-2020.shtml>. Acesso em: 07 mai. 2017.

DIAS, Renata Rampim de Freitas. Internet das Coisas: um futuro que já chegou. RFID Journal Brasil, São Paulo, 31 jan. 2013. Disponível em: $<$ http://brasil.rfidjournal.com/artigos/vision?103 72/>. Acesso em: 07 mai. 2017.

EVANS, D. A Internet das Coisas: como a próxima evolução da Internet está mudando tudo. Cisco Internet Business Solutions Group, San Jose, p. 1-13, abr. 2011. Disponível em: <http://www.cisco.com/c/dam/global/pt_br/asse ts/executives/pdf/internet_of_things_iot_ibsg_0 411final.pdf>. Acesso em: 07 mai. 2017.

FREIRES, T. G. S. Relações entre a Ciência da Informação e as Ciências da Comunicação: um estudo dos conceitos de representação documentária, mediação e comunicação científica. 2007. 202 f. Trabalho de Conclusão de Curso (Bacharelado em Biblioteconomia) Departamento de Biblioteconomia e Documentação da Escola de Comunicações e Artes, Universidade de São Paulo, São Paulo, $2007 . \quad$ Disponível em: <http://rabci.org/rabci/sites/default/files/TCCFreires.pdf>. Acesso em: 07 mai. 2017.

GERHARDT, T. E.; SILVEIRA, D. T. (Orgs.). Métodos de pesquisa. Porto Alegre: UFRGS, 2009. Disponível em: <http://www.ufrgs.br/cursopgdr/downloadsSerie /derad005.pdf>. Acesso em: 07 mai. 2017.

GEUS, P. L.; GRÉGIO, A.; MELO, B. "Coisinhas" da Internet das Coisas. Computação Brasil: Revista da Sociedade Brasileira de Computação, Porto Alegre, n. 29, p. 33-37, abr. 2015. Disponível em: <http://www.sbc.org.br/images/flippingbook/co mputacaobrasil/computa_29_pdf/comp_brasil_2 015_4.pdf >. Acesso em: 07 mai. 2017.

GIL, A. C. Como planejar um projeto de pesquisa. 4. ed. São Paulo: Atlas, 2002.

GREGO, M. Conteúdo digital dobra a cada dois anos no mundo. Exame, São Paulo, 09 abr. 2014. Disponível em: <http://exame.abril.com.br/tecnologia/noticias/c 
onteudo-digital-dobra-a-cada-dois-anos-nomundo>. Acesso em: 07 mai. 2017.

INTERNET... Internet das coisas e o uso de drones contra desastres. Galileu, São Paulo, 24 jul. 2015. Disponível em: $<$ http://revistagalileu.globo.com/Caminhos-paraofuturo/Desenvolvimento/noticia/2015/07/intern et-das-coisas-e-o-uso-de-drones-contradesastres.html>. Acesso em: 07 mai. 2017.

JUNGES, F. M.; KLEIN, A. Z.; BARBOSA, J. L. V. Computação ubíqua: Estado da Arte e Oportunidades de Pesquisa para a Área de Negócios. Revista Eletrônica de Sistemas de Informação, Curitiba, v. 13, n. 1, p. 1-22, jan./abr., $2014 . \quad$ Disponível em: <http://www.periodicosibepes.org.br/index.php/ reinfo/article/view/1505/pdf $>$. Acesso em: 07 maio 2017.

LÉVY, P. A inteligência coletiva: por uma antropologia do ciberespaço. São Paulo: Loyola, 1998.

LÉVY, P. Cibercultura. São Paulo: 34, 1999.

LÉVY, P. O que é o virtual? São Paulo: 34, 1996.

MACHADO, A. Estudo da EMC prevê que volume de dados virtuais armazenados será seis vezes maior em 2020. O Globo, Rio de Janeiro, $10 \mathrm{abr}$. 2014.

Disponível em: <http://oglobo.globo.com/sociedade/tecnologia/ estudo-da-emc-preve-que-volume-de-dadosvirtuais-armazenados-sera-seis-vezes-maior-em2020-12147682>. Acesso em: 07 mai. 2017.

MARCONI, M. A.; LAKATOS, E. M. Fundamentos de metodologia científica. 7.ed. São Paulo: Atlas, 2010.

MARTINO, L. M. S. Teoria das mídias digitais: linguagens, ambientes e redes. 2.ed. Petrópolis: Vozes, 2015.

McEWEN, A; CASSIMALLY, H. Designing the Internet of Things. Chichester: John Wiley \& Sons, 2014. Disponível em: <http://www.shahrvan.org/wpcontent/uploads/2016/06/Designing-TheInternet-Of-Things.pdf>. Acesso em: 07 mai. 2017.
MOHERDAUI, L. Guia de estilo web: produção e edição de notícias on-line. 2.ed. São Paulo: Senac, 2002.

MOREIRA FILHO, J. V. B. Soluções para descoberta de serviços em sistemas ubíquos: uma revisão da literatura. 2014. $39 \mathrm{f}$. Trabalho de Conclusão de Curso (Especialização em Engenharia de Software) - Centro de Ciências e Tecnologia, Universidade Estadual do Ceará, Fortaleza, 2014. Disponível em: <http://www.larces.uece.br/ gesad/wpcontent/ uploads/2015/08/Monografiaespecializa\%C3\%A7 \%C3\%A3o-vers\%C3\%A3o-final.pdf>. Acesso em: 07 mai. 2017.

OLIVEIRA, F. Mercado incipiente, internet das coisas conecta de bueiro a boi. Folha de S.Paulo, São Paulo, 11 set. 2016. Disponível em: <http://www1.folha.uol.com.br/mercado/2016/0 9/1812150-internet-das-coisas-conecta-debueiro-a-boi.shtml>. Acesso em: 07 mai. 2017.

OLIVEIRA, J. F. T.I.C.: tecnologias da informação e da comunicação. São Paulo: Érica, 2003.

PINOCHET, L. H. C. Tecnologia da informação e comunicação. Rio de Janeiro: Elsevier, 2014.

POPOVICl, E. Internet das coisas, computação difusa ou computação ubíqua. HTBRAZ Connect News, São Paulo, 16 jan. 2012. Disponível em: <http://htbraz.blogspot.com.br/2012/01/internet -das-coisas-computacao-difusa.html>. Acesso em: 07 mai. 2017.

SANTAELLA, L. Desafios da ubiquidade para a educação. Revista Ensino Superior Unicamp, Campinas, n. 9, p. 19-28, abr./jun., 2013. Disponível em: $<$ https://www.revistaensinosuperior.gr.unicamp. br/edicoes/edicoes/ed09_abril2013/NMES_1.pdf >. Acesso em: 07 mai. 2017.

SANTOS, B. P.; SILVA, L. A. M.; CELES, C. S. F. S.; BORGES NETO, J. B.; PERES, B. S.; VIEIRA, M. A. M.; VIEIRA, L. F. M.; GOUSSEVSKAIA, O. N.; LOUREIRO, A. A. F. Internet das Coisas: da teoria à prática. 2016. Disponível em: $<$ http://homepages.dcc.ufmg.br/ mmvieira/cc/p apers/internet-das-coisas.pdf>. Acesso em: 07 mai. 2017. 
SILVA, E.; BOTELHO, L.; SANTOS, I.; SANCHEZ, G. Computação ubíqua: definição e exemplos. Revista de Empreendedorismo, Inovação e Tecnologia. Campinas, v. 2, n. 1, p. 23-32, jan. 2015. Disponível em: <https://seer.imed.edu.br/index.php/revistasi/ar ticle/view/926/739>. Acesso em: 07 mai. 2017.

VICENTIN, T. Águas de São Pedro: por dentro da primeira cidade inteligente do Brasil. IT Forum 365, Águas de São Pedro, 18 ago. 2015. Disponível em: <http://www.itforum365.com.br/conectividade/i nternet-das-coisas/aguas-de-sao-pedro-pordentro-da-primeira-cidade-inteligente-do-brasil>. Acesso em: 07 mai. 2017.

W3C. Facts About W3C. 2017. Disponível em: <https://www.w3.org/Consortium/facts\#history. Acesso em: 07 mai. 2017.

WEISER, M. The Computer for the 21st Century. $1991 . \quad$ Disponível em: $<$ https://www.ics.uci.edu/ corps/phaseii/WeiserComputer21stCentury-SciAm.pdf>. Acesso em: 07 mai. 2017.

Recebido para publicação em: 14/05/2017

Revisado em: 06/11/2017

Aceito em: 15/11/2017 